\title{
Téoros
}

Revue de recherche en tourisme

\section{Une Estrie de plus en plus gastronomique}

\section{Réjean Beaudoin}

Volume 3, numéro 3, novembre 1984

Cuisine québécoise, restauration et tourisme : vers une synergie

féconde

URI : https://id.erudit.org/iderudit/1080779ar

DOI : https://doi.org/10.7202/1080779ar

Aller au sommaire du numéro

Éditeur(s)

Université du Québec à Montréal

ISSN

0712-8657 (imprimé)

1923-2705 (numérique)

Découvrir la revue

Citer cet article

Beaudoin, R. (1984). Une Estrie de plus en plus gastronomique. Téoros, 3(3),

26-26. https://doi.org/10.7202/1080779ar d'utilisation que vous pouvez consulter en ligne.

https://apropos.erudit.org/fr/usagers/politique-dutilisation/ 


\title{
Une Estrie de plus en plus gastronomique
}

\author{
par Réjean Beaudoin *
}

Normalement, c'est l'ensemble des attraits, des activités et des services touristiques disponibles qui justifient un déplacement individuel ou en groupe vers un milieu donné. Pour qu'il y ait un dêplacement, il s'avère nécessaire que la somme des contraintes qui s'y rapportent soit moindre que la somme des forces attractives d'une offre touristique.

Ainsi, plus une localité ou une région ajoute de composantes positives à son produit touristique global, plus ce produit attire les visiteurs.

A ce chapitre, puisque plusieurs études démontrent qu'entre $15 \%$ et $25 \%$ des dépenses touristiques sont reliées à la res. tauration, la gastronomie doit obligatoirement faire partie de ces nouvelles additions.

\section{La gastronomie: un attrait}

Le développement du tourisme ne concerne pas exclusivement la mise en valeur d'un lieu territorial..., il fait également référence à la cuisine locale ou régionale qui peut présenter un intérêt certain pour les visiteurs.

II est connu et reconnu que les touristes adorent et apprécient les expressions culturo-gastronomiques d'un milieu, surtout lorsque les ingrédients sont issus de la production agricole locale.

Les visiteurs recherchent la nouveauté, la différence, l"inhabituel. La gastronomie, sous l'impulsion de la créativité, peut combler ces aspirations. La prolifération des restaurants et salles à manger, inscrivant quelques plats typiquement régionaux sur leur menu, est sans contredit fort souhaitable pour l'industrie touristique d'une région comme celle de l'Estrie.

\section{Vers une \\ "fine cuisine estriennen}

Depuis plusieurs décennies, la cuisine à saveur estrienne offerte aux touristes gravitait uniquement autour du Canard du lac Brome, apprèté de diverses façons. Tout en respectant ce mets succulent, la mise en valeur d'une nouvelle gastronomie typique à l'Estrie, decoulant de sa production agricole, a été une préoccupation quasi constante depuis la fondation de l'Association touristique de l'Estrie (A.T.E), en mars 1978.

En plus d'assurer lá présence d'un éventail acceptable de plats régionaux, I'A.T.E visait aussi les trois (3) objectifs suivants: - inspirer à la population de l'Estrie et à son industrie touristique une grande fierté face à une nouvelle gastronomie estrienne;

- élever une nouvelle gastronomie estrienne au stade d'un réel attrait touristique:

- augmenter, en région, l'impact économique du tourisme, par la création d'une nouvelle gastronomie utilisant des produits agricoles de l'Estrie.

Sur cette base, l'Association touristique de l'Estrie a soumis un projet de création de cette cuisine au Centre de recherches technologiques (C.R.T.) de I'Institut de tourisme et d'hôtellerie du Québec (I.T.H.O). afin de bénéficier de son expertise.

L'A.T.E. a ensuite entrepris des démarches auprès de I'Union des producteurs agricoles de I'Estrie (U.P.A) et du bureau régional du ministere de I'Agriculture, des Pêcheries et de l'Alimentation du Québec. dans le but de répertorier l'ensemble de la production agricole de I'Estrie. Après analyse, ils ont pu retenir des types de production susceptibles de contribuer ả la naissance d'une nouvelle gastronomie estrienne en tenant compte des objectifs cités.

Une fois cette étape franchie, le personnel du C.R.T. a procédé à diverses expérimentations de recettes qui ont été soumises aux membres du comité de gastronomie de I'Association touristique de I'Estrie. II en est découlé l'acceptation de treize (13) recettes composées d'ingrédients locaux.

Par la suite, persuadés de l'originalité et de la qualité des plats retenus, les membres du comité de gastronomie de l'A.T.E. ont décidé de réunir ces recettes dans un recueil sous le titre $\mathrm{La}$ fine cuisine estrienne. Ce document vise à publiciser les recettes et à convaincre les Estriens, et particulièrement les restaurateurs, á déguster ces mets et â les faire déguster. Ce recueil fut lancé officiellement le 11 juillet 1984.

\section{Le devenir concret}

La publication du recueil et les interventions se rapportant au projet visent à sensibiliser la population et l'industrie de la restauration à l'importance d'utiliser les produits locaux au sein de la gastronomie.

Pour I'instant, la population reçoit des informations à ce sujet par l'entreprise des médias et lors de divers événements spéciaux. Le recueil est également distribué par le biais d'un réseau de vente régional regroupant une cinquantaine $(50)$ d'entre. prises dont les succursales de la Société des alcools du Québec, plusieurs auberges, restaurants, librairies et boutiques. Récemment, les quotidiens de l'Estrie ont mani. festé leur intention de publier á l'occasion quelques recettes. De plus, un concept de club de afine cuisine estriennes pourrait voir le jour.

Cette promotion vise à faire naïtre graduellement une forme de sentiment d'appartenance et de fiertể relativement ă la dégustation de ces recettes à domicile. On sou. haite également amener les citoyens à réclamer de plus en plus ces mets chez leurs restaurateurs préférés. On considère. que dans certaines parties de la région, c'est I'habitude de la consommation locale qui assurera la popularité des mets auprès des visiteurs.

Quant à l'industrie proprement dite, dans l'immédiat, on privilégie quatre (4) moyens de promotion, soit:

- l'enseignement des recettes dans les cours de cuisine réguliers dispensés dans la région;

- l'organisation, sur une base ponctuelle. de cours intensifs menant à la remise d'un certificat spécial;

- la création d'un mérite culinaire annuel destiné aux entreprises et aux chefs:

- une promotion continuelle aupres des entreprises afin que les recettes deviennent de plus en plus présentes sur leurs menus. Quelques auberges et restaurants ont deja commencé à offrir à leurs clientéles locale et touristique certains plats de la nouvelle cuisine estrienne. Les plus récentes informations nous indiquent que ces plats sont reçus positivement. On dénote également chez les restaurateurs un désir manifeste de persévérer dans cette voie. $f$ 